\title{
Effect of urbanisation on the relationship between total serum IgE and asthma
}

\author{
William Checkley*,\#, , Colin L. Robinson*, Lauren M. Baumann*, Karina Romero+,

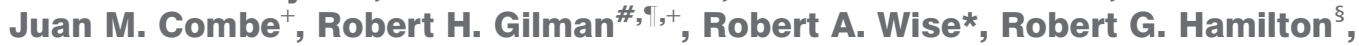 \\ Guillermo Gonzalvez ${ }^{f}$, Vitaliano Cama**, Nadia N. Hansel ${ }^{\star, \# \#}$ and the PURA \\ study investigators
}

ABSTRACT: It is unclear if the relationship of total serum IgE with asthma varies with degree of urbanisation. We hypothesised that the relationship of total serum IgE to asthma is more pronounced in an urban versus a rural environment.

We enrolled 1441 children aged 13-15 years in a peri-urban shanty town in Lima, Peru $(n=725)$ and 23 villages in rural Tumbes, Peru $(n=716)$. We asked participants about asthma and allergy symptoms, environmental exposures and sociodemographics; and performed spirometry, and exhaled nitric oxide and allergy skin testing. We obtained blood for total serum IgE in 1143 (79\%) participants.

Geometric means for total serum IgE were higher in Lima versus Tumbes (262 versus $\left.192 \mathrm{kU} \cdot \mathrm{L}^{-1} ; \mathrm{p}<0.001\right)$. The odds of asthma increased by factors of $1.6(95 \% \mathrm{Cl} 1.3-2.0)$ versus 1.4 (95\% $\mathrm{Cl}$ 0.9-2.1) per log unit increase in total serum IgE in Lima versus Tumbes, respectively. Atopy was an effect modifier of the relationship of total serum IgE on asthma. Among atopics and non-atopics, the odds of asthma increased by a factor of 2.0 (95\% Cl 1.5-2.7) and 1.0 (95\% Cl 0.71.4) per log unit increase in total serum IgE, respectively.

Total serum IgE was associated with atopic asthma but not with non-atopic asthma. Urbanisation did not appear to be an effect modifier of this relationship.

\section{KEYWORDS: Asthma clinical/basic investigations, atopic asthma, epidemiology of asthma}

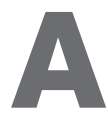
sthma is a chronic lung disease that is associated with an inflammatory reaction of the airways, bronchial hyperresponsiveness and increased production of mucus, all which lead to reversible periods of airway obstruction. Over the past several decades, asthma has emerged as one of the most prevalent non-communicable diseases worldwide, particularly among children. It currently affects 300 million individuals around the world, is responsible for 255000 deaths and results in 15 million disability-adjusted life-years lost each year [1]. The worldwide burden of disease caused by asthma accounts for one per cent of all disability life years lost, and is comparable to that of diabetes mellitus or cirrhosis [2,3].

Atopic sensitisation is a well-known risk factor for the development of asthma [4], and repeated exposure to high levels of allergens with previous sensitisation can worsen asthma control $[5,6]$. The development of an allergic response is mediated by the production of IgE antibodies. Since the discovery of $\operatorname{IgE}[7]$, the relationship of total serum IgE with asthma [8-13] has been extensively studied to determine if it could be a useful adjunct in the diagnosis of asthma. However, due to considerable overlap in total serum IgE levels among atopic and non-atopic populations, the diagnostic utility of total serum IgE for asthma has been questioned. Moreover, sensitisation to specific allergens may occur even in the setting of low total serum IgE levels. Interpretation of total $\mathrm{IgE}$ in developing countries is complicated even further with a high burden of parasitic infections.

While the relationship of total serum IgE to asthma is well described in developed countries, it is unclear if this relationship varies in different populations according to the types of allergens, levels of indoor and outdoor air pollution, the prevalence of atopy or parasitic infections [14] and other risk factors for asthma, including obesity [15] and degree of urbanisation. In this study, we examined the relationship of total
AFFILIATIONS

*Division of Pulmonary and Critical Care, School of Medicine, Johns Hopkins University, Baltimore, MD

\#Program in Global Disease

Epidemiology and Control, Dept of International Health, Bloomberg School of Public Health, Johns Hopkins University, Baltimore, MD,

${ }^{\S}$ Division of Allergy and Clinical Immunology, School of Medicine, Johns Hopkins University, Baltimore, MD,

**Division of Parasitic Diseases, National Center for Infectious Diseases, Centers for Disease Control and Prevention, Atlanta, GA, and \#\#Dept of Environmental Health Sciences, Bloomberg School of Public Health, Johns Hopkins University, Baltimore, MD, USA.

"CRONICAS Center of Excellence for Chronic Disease Research, Universidad Peruana Cayetano Heredia, Lima, +Asociación Benéfica PRISMA, Lima, and

${ }^{\dagger}$ Departamento de Microbiologia, Universidad Peruana Cayetano Heredia, Lima, Peru.

\section{CORRESPONDENCE}

W. Checkley

Division of Pulmonary and Critical Care

School of Medicine

Johns Hopkins University

1800 Orleans Street

Suite 9121

Baltimore

MD 21205

USA

E-mail: wcheck11@jhmi.edu

Received:

Feb 102012

Accepted after revision:

June 152012

First published online:

July 262012 
serum IgE with asthma, atopy, airway obstruction and airway inflammation in two regions of a developing country with disparate degrees of urbanisation and a different profile of environmental exposures. We hypothesised that the relationship of total serum IgE to asthma may be more pronounced in an urban than in a rural environment.

\section{METHODS}

\section{Study design}

The study design is described in detail elsewhere [16-18]. We conducted a population-based, cross-sectional study of asthma prevalence in two regions in Peru. In December 2008, we selected a random sample of children aged 13-15 years from a community census and visited them for enrolment between April 2009 and December 2010. The first site was Lima, the highly urbanised capital of Peru, located at sea level and with a population of 10 million. We conducted our study in Pampas de San Juan de Miraflores, a peri-urban shanty-town located $25 \mathrm{~km}$ south of central Lima. The second site was rural Tumbes, also at sea level, located in northern Peru. We asked about asthma and allergy symptoms, sociodemographics and environmental exposures, and obtained anthropometry, a blood sample, allergy skin test, exhaled nitric oxide test, and spirometry before and after bronchodilators. The basis of questionnaire used in this study was a previously validated Spanish version of the International Study of Asthma and Allergies in Childhood study [19]. We conducted spirometry according to American Thoracic Society/European Respiratory Society guidelines [20] with the portable SpiroPro (Jaeger, Hoechberg, Germany). We used the handheld NIOXMINO (Aerocrine, Solna, Sweden) to measure exhaled nitric oxide. We performed allergy tests with the Multi-Test II (Lincoln Diagnostics, Decatur, USA) using 10 common household allergens [17]. Serum specimens were analysed for total serum IgE using an USA Food and Drug Administration cleared fluorescent enzyme immunoassay (ImmunoCAP250, Thermo Fisher Scientific, Kalamazoo, MI, USA). We obtained approval from the ethics committees of A.B. PRISMA in Lima, Peru, and the Johns Hopkins University, Bloomberg School of Public Health, in Baltimore, MD, USA.

\section{Definitions}

We defined asthma as wheeze in the past 12 months or use of asthma medications in the past 12 months. We defined atopy as a positive skin response to any of the allergen specificities as previously described $[17,18]$. Briefly, an allergy skin test was considered positive if the sum of the vertical and horizontal dimensions of the induration was $>3 \mathrm{~mm}$ larger than the negative control or if the sum of the vertical and horizontal dimensions of erythema was $>5 \mathrm{~mm}$ larger than the negative control. We defined reversibility as a $12 \%$ increase in post- to pre-forced expiratory volume in $1 \mathrm{~s}$ (FEV1).

\section{Biostatistical methods}

Our primary objective was to study the relationship of total serum IgE to asthma. We used multivariable logistic regression stratified by site and by atopic status and adjusted for age, sex, body mass index $\left(>25 \mathrm{~kg} \cdot \mathrm{m}^{-2}\right)$, personal history of tobacco smoke, second-hand tobacco smoke and sociodemographics including maternal education ( $<6$ years), monthly household income ( $<175$ USD), household density (more than six people per household) and concrete floor. The distribution of total serum $\operatorname{IgE}$ was skewed left, with values that ranged from 2 to $9420 \mathrm{kU} \cdot \mathrm{L}^{-1}$. Thus, we $\log$ transformed values of total $\operatorname{IgE}$ for statistical analyses. In exploratory analyses, we found that the relationship of $\log$ total $\operatorname{IgE}$ to the $\log$ odds of asthma was approximately linear. We also studied the relationship of total IgE to airway obstruction as measured by the ratio of FEV1 to forced vital capacity (FVC). We conducted multivariable linear regression stratified by site and asthma status and adjusted for the same sociodemographic variables. Secondary objectives included analyses of the relationship of total $\operatorname{IgE}$ to both atopy and airways inflammation as measured by an exhaled nitric oxide greater than $40 \mathrm{ppm}$. We used multivariable logistic regression adjusted by sociodemographics for these analyses. Finally, we used t-tests to compare the log transformed values of total $\mathrm{IgE}$ and chi-squared tests for differences in proportions across strata. Analyses were restricted to the subgroup of 1143 participants for which we had a total serum IgE measurement. We used R (www.r-project.org) for statistical analyses.

\section{RESULTS}

\section{Baseline characteristics}

Of 1441 children who agreed to participate in the study, we obtained blood samples for total serum IgE levels from 1143 $(79 \%)$. There were no differences observed in the age $(p=0.97)$, sex $(p=0.70)$, prevalence of asthma $(p=0.72)$ or atopy $(p=0.24)$, pre-FEV1/FVC $(p=0.69)$, exhaled nitric oxide $(p=0.35)$, body mass index $(\mathrm{p}=0.40)$, income $(\mathrm{p}=0.66)$ and maternal education $(p=0.73)$ between participants with and without a blood sample for total serum IgE levels. Children living in the urban environment were less likely to live in households with a monthly income $<175$ USD ( $25 \%$ versus $63 \%$; $p<0.001$ ), were more likely to live in households with uninterrupted water services $(92 \%$ versus $6 \% ; p<0.001)$ or electricity $(100 \%$ versus $85 \% ; \mathrm{p}<0.001)$, were more likely to have an indoor sewage connection ( $92 \%$ versus $27 \%$; $<<0.001)$, and were less likely to live in households with regular use of biomass fuels ( $9 \%$ versus $42 \%$; $<0.001)$ or farm animals $(72 \%$ versus $23 \%$; $<<0.001)$ than those in the rural environment.

The mean \pm SD total serum IgE was $588 \pm 883 \mathrm{kU} \cdot \mathrm{L}^{-1}$ in Lima and $407 \pm 679 \mathrm{kU} \cdot \mathrm{L}^{-1}$ in Tumbes $(\mathrm{p}<0.001$; t-test of $\log \operatorname{IgE})$; however,

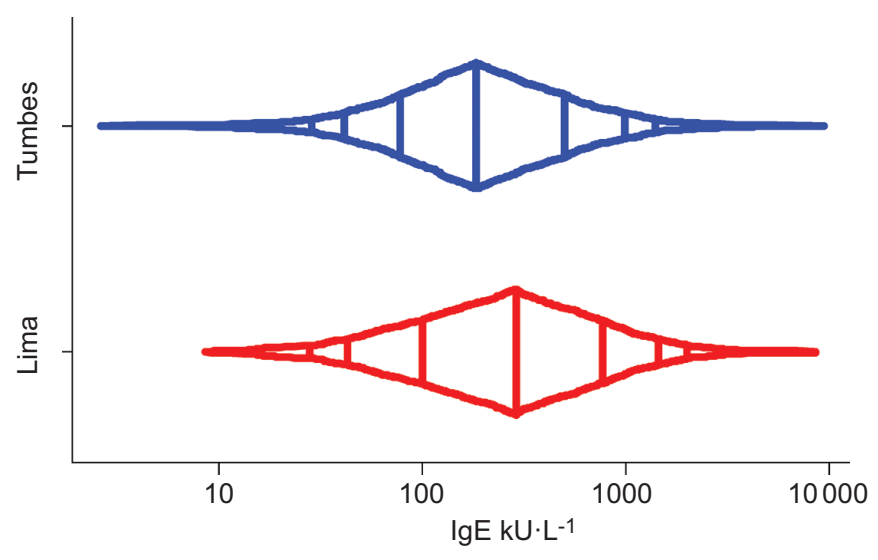

FIGURE 1. Distribution of total serum IgE stratified by site; Peru, 2009-2010. xaxis is in log-scale. Vertical lines inside the box-percentile plot represent, from left to right, the 5th, 10th, 25th, 50th, 75th, 90th and 95th percentiles, respectively. 
TABLE 1 IgE levels across demographic variables, asthma status, atopic status, airways inflammation and socioeconomic variables, stratified by study site; Peru, 2009-2010

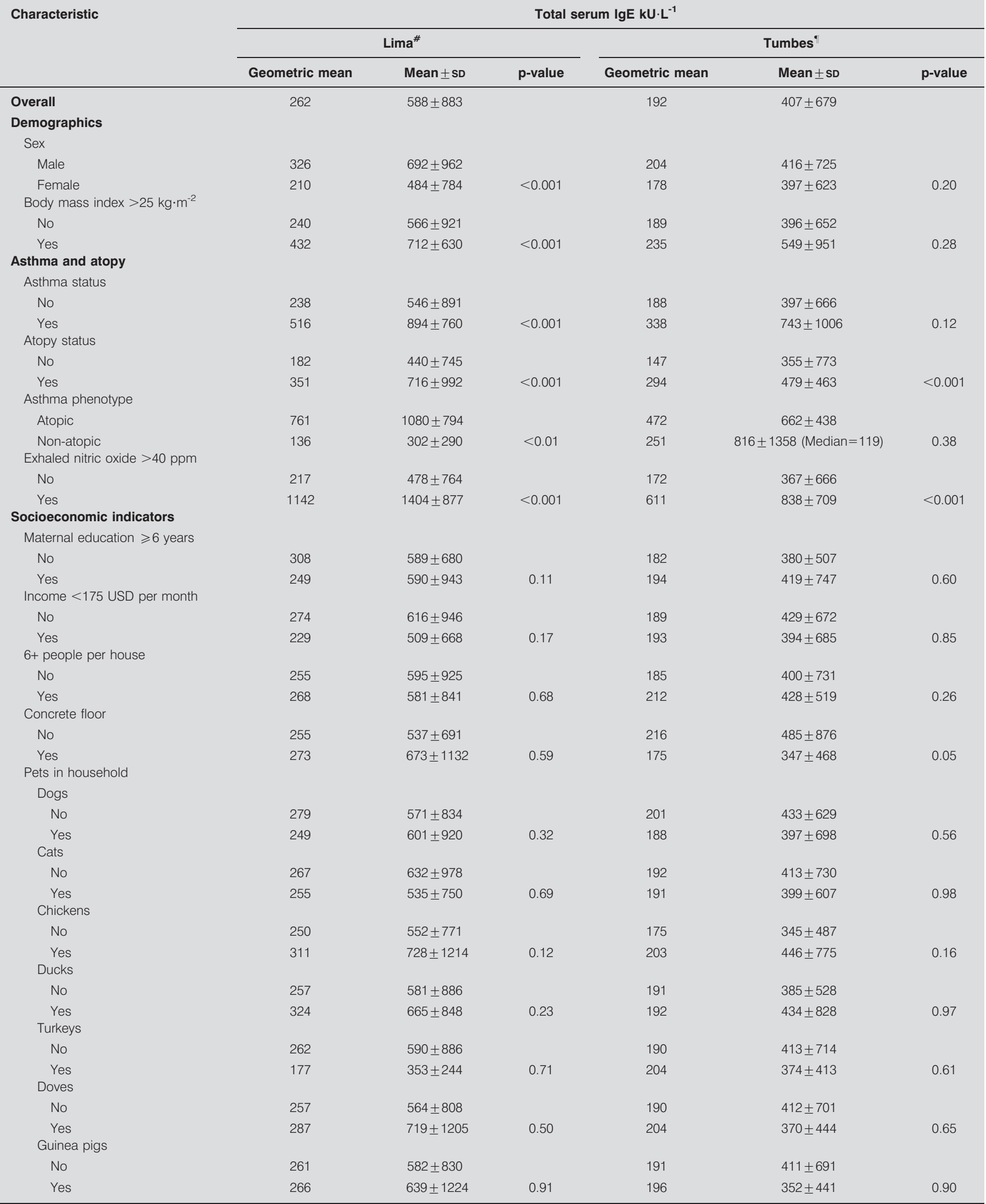

${ }^{\#}: n=566 ; ": n=577$. 


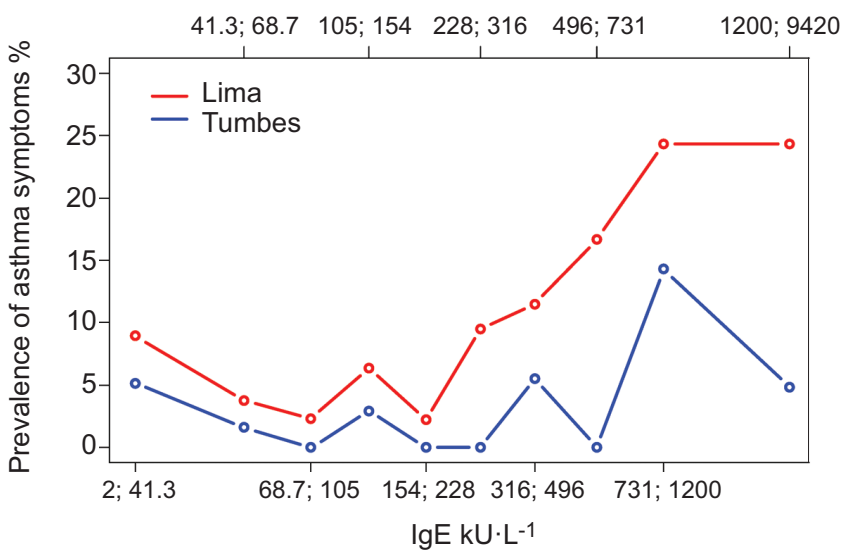

FIGURE 2. Prevalence of asthma by deciles of total serum IgE stratified by study site; Peru, 2009-2010. Decile interval values are indicated as $x ; y$ corresponding to values greater than $x$ and including $y$.

there was considerable overlap in the range of total IgEs between sites (fig. 1). Corresponding geometric means were $262 \mathrm{kU} \cdot \mathrm{L}^{-1}$ and $192 \mathrm{kU} \cdot \mathrm{L}^{-1}$, respectively. Average mean $\pm \mathrm{SD}$ age at the time of enrolment was comparable in both study groups, $14.8 \pm 0.9$ years in Lima versus $14.9 \pm 0.9$ years in Tumbes $(p=0.44)$. In Lima, total IgE levels were higher in boys than in girls and higher in overweight participants (body mass index $>25 \mathrm{~kg} \cdot \mathrm{m}^{-2}$ ) than in those who were not overweight (table 1). While these differences were not statistically significant in Tumbes, they trended in the same direction. We did not find significant differences in average total serum IgE levels across select socioeconomic indicators such as maternal education, monthly income or household density in either site (table 1).

Pets and farm animals were commonly found in households at both sites. There was a greater proportion of households with dogs $(72 \%$ versus $57 \%$; $<<0.001)$, chickens ( $61 \%$ versus $21 \%$; $\mathrm{p}<0.001)$, ducks $(45 \%$ versus $9 \%$; $<<0.001)$ and turkeys $(14 \%$ versus $<1 \%$; $<<0.001)$ in Tumbes than in Lima. There was a similar proportion of households with cats ( $43 \%$ versus $45 \%$; $\mathrm{p}=0.52$ ) in Tumbes and Lima. There was a greater proportion

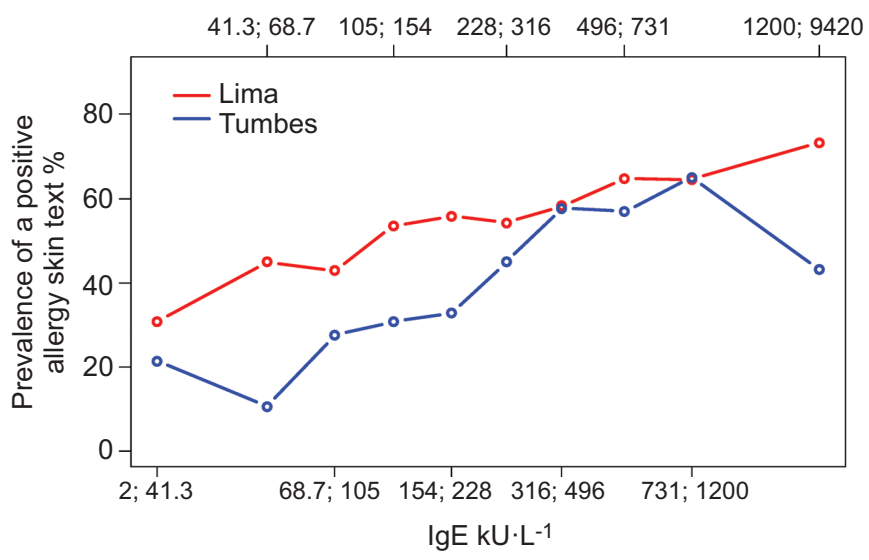

FIGURE 3. Prevalence of atopy by deciles of total serum IgE stratified by study site; Peru, 2009-2010. Decile interval values are indicated as $x ; y$ corresponding to values greater than $x$ and including $y$.

of households with doves $(16 \%$ versus $10 \%$; $\mathrm{p}<0.01)$ and guinea pigs $(12 \%$ versus $6 \%$; $<0.001)$ in Lima than in Tumbes. Total serum IgE levels were not affected by the presence of pets or farm animals at either site (table 1$)$. Dogs ( $38 \%$ versus $13 \%$; $\mathrm{p}<0.001)$ and cats $(76 \%$ versus $32 \% ; \mathrm{p}<0.001)$ were more likely to be exclusively indoors in Lima than in Tumbes. The prevalence of atopic sensitisation was significantly greater in Lima than in Tumbes for all tested allergens. While the rate of atopic sensitisation was slightly greater for cockroach $(57 \%$ versus $42 \%$; $<<0.001)$, mite $(58 \%$ versus $35 \%$; $p<0.001)$ and cat ( $55 \%$ versus $32 \% ; \mathrm{p}<0.001)$, it was substantially greater for $\mathrm{dog}$ $(52 \%$ versus $13 \% ; \mathrm{p}<0.001)$, mouse $(52 \%$ versus $19 \%$; $\mathrm{p}<0.001)$ and mould ( $53 \%$ versus $15 \% ; \mathrm{p}<0.001)$.

\section{Relationship of total serum IgE to asthma, atopy and airways inflammation}

Among the 1143 participants with a total serum IgE measurement, the prevalence of atopy as assessed by skin testing was $55 \%$ (292 out of 527) in Lima and 37\% (206 out of 550) in Tumbes. The prevalences of atopic and non-atopic asthma in Lima were $17 \%$ (50 out of 292) and 6\% (13 out of 235),

TABLE 2 Multiple variable regression of predictors of asthma stratified by atopic status; Peru, 2009-2010

Variable

OR $(95 \% \mathrm{Cl})$

log total serum $\lg \mathrm{E} \mathbf{k U} \cdot \mathrm{L}^{-1}$

Body mass index $>25 \mathrm{~kg} \cdot \mathrm{m}^{-2}$

Maternal education $\geqslant 6$ years

$6+$ people per house

Income <175 USD per month

Concrete floor

Female sex

Age

Personal history of tobacco smoke

Second-hand tobacco smoke

\begin{tabular}{cccc}
\hline Atopic asthma\# $^{\#}$ & p-value & Non-atopic asthma & p-value \\
$1.9(1.4-2.6)$ & $<0.001$ & $1.0(0.7-1.4)$ & 0.91 \\
$3.5(1.7-7.1)$ & 0.001 & $2.4(0.8-7.3)$ & 0.11 \\
$1.4(0.6-2.9)$ & 0.43 & $0.9(0.3-2.3)$ & 0.79 \\
$1.8(1.0-3.4)$ & 0.07 & $0.9(0.4-2.2)$ & 0.83 \\
$0.6(0.3-1.3)$ & 0.20 & $0.6(0.2-1.3)$ & 0.22 \\
$0.6(0.3-1.2)$ & 0.13 & $0.8(0.3-1.8)$ & 0.59 \\
$0.7(0.4-1.2)$ & 0.24 & $1.6(0.6-3.6)$ & 0.32 \\
$1.0(0.7-1.4)$ & 0.99 & $0.9(0.5-1.4)$ & 0.59 \\
$2.1(0.7-6.4)$ & 0.20 & $1.6(0.2-13.9)$ & 0.67 \\
$0.5(0.2-1.3)$ & 0.18 & $0.5(0.1-2.1)$ & 0.32 \\
\hline
\end{tabular}

\#: $n=461 ; \bullet: n=541$ 


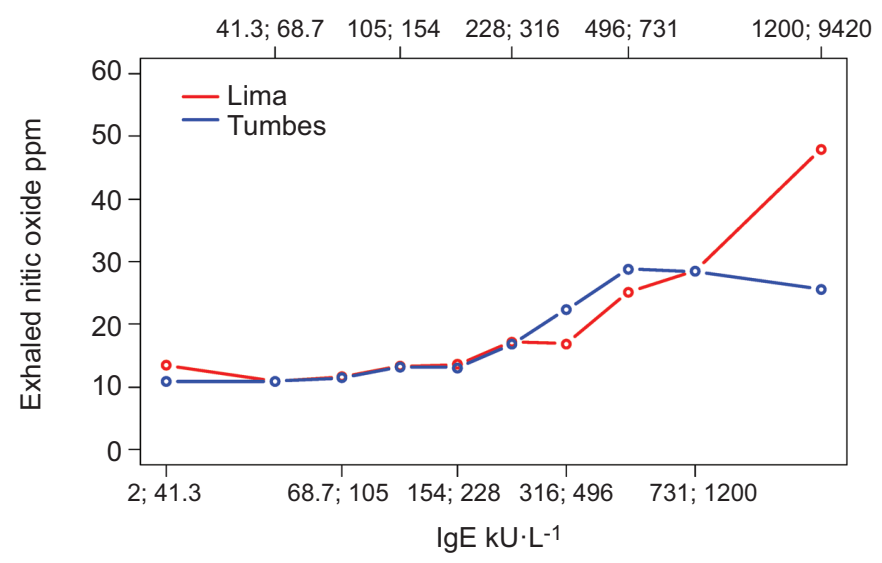

FIGURE 4. Mean levels of exhaled nitric oxide ppm by deciles of total serum IgE stratified by study site; Peru, 2009-2010. Decile interval values are indicated as $x ; y$ corresponding to values greater than $x$ and including $y$.

respectively; in Tumbes, the corresponding prevalences of atopic and non-atopic asthma were $4 \%$ (eight out of 206) and $3 \%$ (nine out of 344), respectively.

Total serum IgE levels were higher in asthmatics than in nonasthmatics (table 1). The prevalence of asthma across our sample increased with total serum IgE (fig. 2). This increase was more apparent in Lima than in Tumbes. In multivariable analyses, the odds of asthma increased by factors of 1.6 (95\% CI 1.3-2.0) and 1.4 (95\% CI 0.9-2.1) per log unit increase in total serum IgE in Lima and in Tumbes, respectively. In pooled analysis, the odds of asthma increased by a factor of 1.6 (95\% CI 1.3-1.9) per log unit increase in total serum IgE. Further stratified analyses revealed that atopy was an effect modifier of the relationship of total $\operatorname{IgE}$

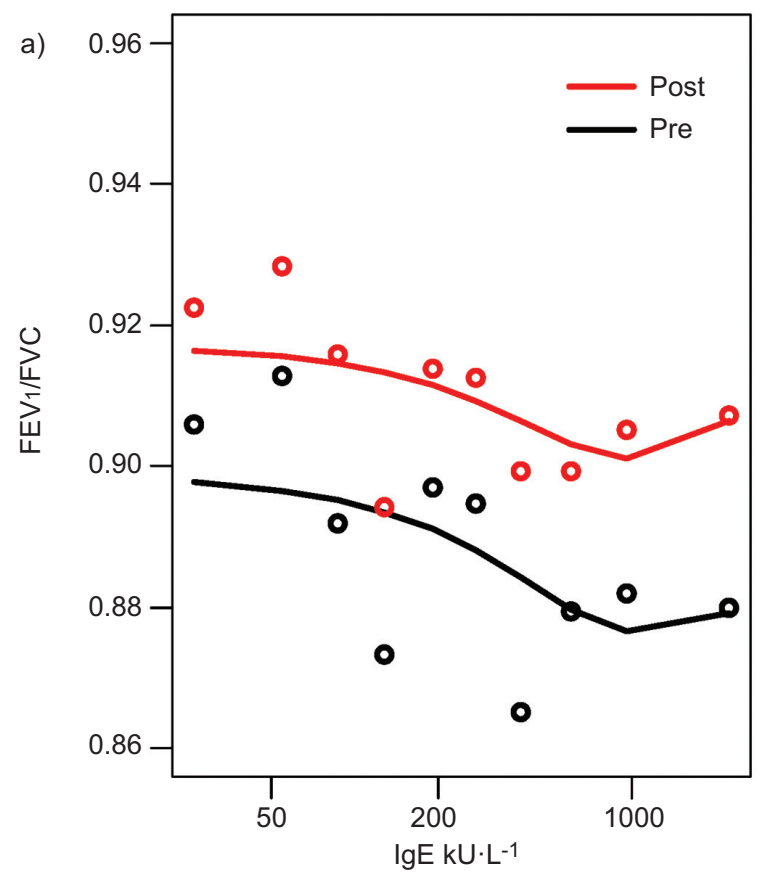

to asthma (table 2). More specifically, total serum IgE was associated with asthma only among those who were atopic.

Total serum IgE levels were also higher in atopics than in nonatopics, and in participants with exhaled nitric oxide $>40 \mathrm{ppm}$ versus those with lower values (table 1 ). The prevalence of atopy across our sample increased with total serum $\operatorname{IgE}$, and this increase was consistent across sites (fig. 3). In multivariable analyses, the odds of atopy increased by factors of 1.5 (95\% CI 1.3-1.7) and 1.6 (95\% CI 1.4-1.9) per log unit increase in total serum IgE in Lima and in Tumbes, respectively. Mean exhaled nitric oxide increased with total serum $\operatorname{IgE}$, and this increase was consistent across sites (fig. 4). The odds of exhaled nitric oxide $>40 \mathrm{ppm}$ increased by factors of 4.0 (95\% CI 2.7-5.8) and 2.5 (95\% CI 1.9-3.4) per log unit increase in total serum $\operatorname{IgE}$ in Lima and in Tumbes, respectively. In pooled analysis, the odds of having exhaled nitric oxide $>40$ ppm increased by a factor of 3.0 (95\% CI 2.4-3.8) per log unit increase in total serum IgE. When stratified by atopic status, the odds of having exhaled nitric oxide $>40 \mathrm{ppm}$ increased by a factor of 2.3 (95\% CI 1.6-3.3) in non-atopics and 3.7 (95\% CI 2.6-5.1) in atopics. This relationship remained significant even among those without asthma. Among nonasthmatics, the odds of having exhaled nitric oxide $>40 \mathrm{ppm}$ increased by factors of 3.6 (95\% CI 2.3-5.5) and 2.5 (95\% CI 1.83.3) per $\log$ unit increase in total serum IgE in Lima and in Tumbes, respectively.

\section{Relationship of total serum IgE to airway obstruction and airway reversibility}

Pre- and post-FEV1/FVC were inversely related to total serum IgE levels in Lima but not in Tumbes (fig. 5). In Lima, mean preand post-FEV1/FVC decreased by $0.5 \%$ (95\% CI $-0.9 \%--0.1 \%)$ and $0.3 \%(95 \% \mathrm{CI}-0.7 \%-0.0 \%)$ per log unit increase in total

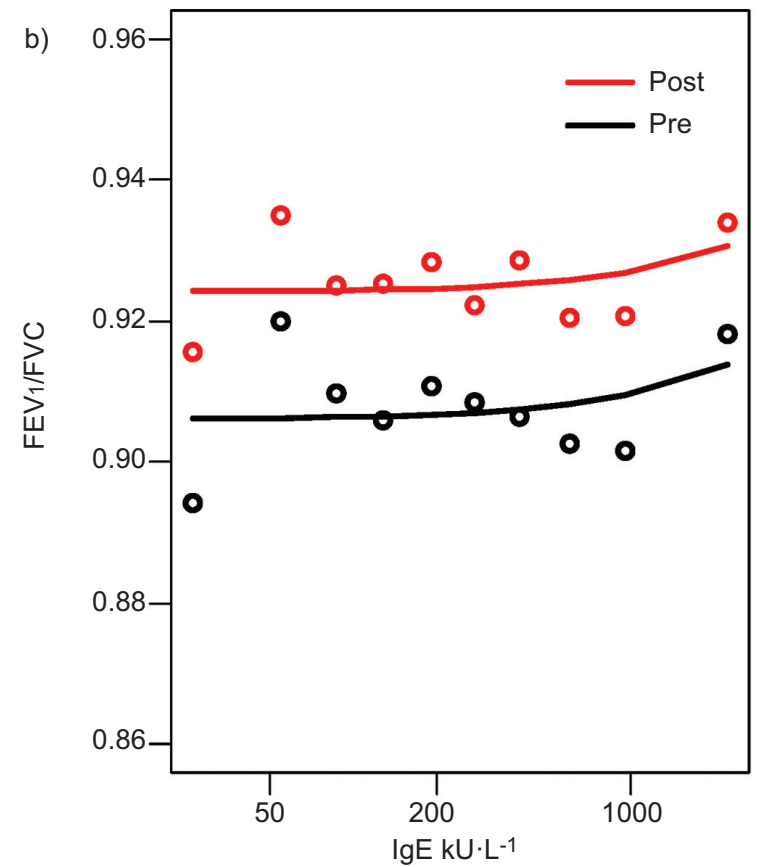

FIGURE 5. Mean pre- and post-forced expiratory volume in $1 \mathrm{~s}$ (FEV1)/forced vital capacity (FVC) by deciles of total serum lgE stratified by study site; a) Lima and b) Tumbes, Peru, 2009-2010. 
serum $\operatorname{IgE}$, respectively. In a similar analysis in the subset of children without asthma, higher total serum IgE levels were also associated with lower pre- and post-FEV1/FVC. Specifically, among non-asthmatics, mean pre- and post-FEV1/FVC decreased by $0.5 \%(95 \% \mathrm{CI}-0.9 \%--0.1 \%)$ and $0.4 \%(95 \% \mathrm{CI}$ $-0.8 \%-0.0 \%$ ) per log unit increase in total serum IgE, respectively. There were too few children with asthma and a total serum $\operatorname{IgE}(n=66)$ to adequately examine dose response relationships between total serum $\operatorname{IgE}$ measurements and FEV1/FVC. In Tumbes, the mean pre-FEV1/FVC $(p=0.65)$ and post-FEV1/FVC $(p=0.75)$ was not associated with total serum IgE levels.

Higher levels of total serum IgE were also associated with more bronchodilator reversibility. More specifically, in multivariable analysis, the odds of airway reversibility increased by factors of 1.4 (95\% CI 1.0-2.1) and 1.4 (95\% CI 0.9-2.1) per log unit increase in total IgE in Lima and in Tumbes, respectively. In pooled analysis, the odds of airway reversibility increased by a factor of 1.4 (9\% CI 1.1-1.9) per log unit increase in total IgE.

\section{DISCUSSION}

Among our sample of Peruvian children aged 13 to 15 years, total serum IgE levels were higher compared to children in the USA or Europe and directly related to the prevalence of atopic asthma but not to that of non-atopic asthma. The relationship of total serum IgE to atopic asthma was consistent across two regions with disparate degrees of urbanisation. Airway inflammation, as measured by exhaled nitric oxide, and bronchodilator reversibility was also greater with higher levels of total serum IgE. The association between total serum $\operatorname{IgE}$ and exhaled nitric oxide remained significant in the subset of children without asthma. In addition, the degree of airways obstruction as measured by FEV1/FVC was worse with increasing total serum IgE in Lima but not in Tumbes. This inverse association of total serum $\operatorname{IgE}$ and FEV1/FVC remained significant in the subset of children without asthma living in the urban environment of Lima.

Our findings on the relationship of total $\mathrm{IgE}$ to asthma by atopic status were consistent with those of a recent survey conducted by the US National Health and Nutrition Examination Study (NHANES) between 2005 and 2006 [12]. Our data provide complementary information to the NHANES analysis in that we further examined the relationship of total $\operatorname{IgE}$ to quantitative measures of airways obstruction and airway inflammation. An important difference between our study and the NHANES study was that the geometric mean of total serum $\operatorname{IgE}$ of our study was approximately four times greater than that of children aged 12 to 15 years in the NHANES sample; however, the relationship of total $\operatorname{IgE}$ to atopic asthma persisted despite these elevated levels. There are several reasons why total serum IgE may be higher in our Peruvian population than in the general population in the USA. One possibility for this increase is the higher prevalence of enteric infections, including protozoans [21, 22], and soil-based helminths [14] in Peru than in the USA. However, the levels of total serum IgE in our sample of Peruvian children were not as high as in other regions with high levels of parasitism [14]. The geometric means between asthmatics and non-asthmatics in our study were similar in magnitude to those identified in a smaller, cross-sectional study of 198 children aged 10 to 13 years conducted in Costa Rica [23].
As with the study in Costa Rica, we did not examine stool samples for ova and parasites in our study children. However, the prevalence of soil-based helminthic infections in children of similar age in our study areas is low (online supplementary material) and therefore unlikely to explain the higher levels of total serum IgE when compared with values of similarly aged children in the NHANES sample.

On the other hand, our findings were different from those of a large general population study of 2657 subjects in Tucson, USA [8], 1916 young adults in five areas of Spain [10] and 1219 consecutive pulmonary patients to a pulmonary practice in Frankfurt, Germany [11], in that we did not find a direct relationship between total serum $\mathrm{IgE}$ and non-atopic asthma. The Tucson study tested 18 allergens by prick test; however, this study did not include allergens for common household pets such as cats and dogs, and household pests such as cockroaches and mice. In contrast, our study and the NHANES study [12] tested for these common household allergens. It is possible that several asthmatics in the Tucson study were misclassified as non-atopic and this could explain why there was a linear relationship of total IgE to non-atopic asthma. In our study, geometric means for total $\operatorname{IgE}$ for atopic asthmatics were $754 \mathrm{kU} \cdot \mathrm{L}^{-1}$ in Lima and $472 \mathrm{kU} \cdot \mathrm{L}^{-1}$ in Tumbes, higher than those in the Tucson study. The geometric means for total $\operatorname{IgE}$ for non-atopic asthmatics were $137 \mathrm{kU} \cdot \mathrm{L}^{-1}$ in Lima and $251 \mathrm{kU} \cdot \mathrm{L}^{-1}$ in Tumbes, also higher than those in the Tucson study. The Spanish study also tested fewer (i.e. five) allergen specificities than ours (i.e. 10) and the NHANES study, and as a result may have had a similar degree of misclassification. The Frankfurt study, unlike our study and others [8, 10, 12], was not a population study but included a large range of 14 common allergens, that did not include cockroach or mouse, and eight food allergens. In this study, the odds of asthma increased by a factor of 5.1 (95\% CI 2.6-10.1) when total serum $\mathrm{IgE}$ was greater than $150 \mathrm{kU} \cdot \mathrm{L}^{-1}$. In contrast, in our study, there was no single cut-off for total serum $\operatorname{IgE}$ between $100 \mathrm{kU} \cdot \mathrm{L}^{-1}$ and $800 \mathrm{kU} \cdot \mathrm{L}^{-1}$ that was associated with non-atopic asthma. Possible explanations for an effect are that the Frankfurt study included a more select group of asthmatics that sought attention for respiratory complaints or follow-up, and their sample of non-atopic asthmatics was larger than ours. However, the Frankfurt study did not include normal healthy controls from the general population.

Our study also identified a greater chance of airway reversibility and greater levels of airways inflammation at higher levels of total serum IgE. This finding is consistent with previous studies that found a relationship between $\operatorname{IgE}$ and more labile airways [24, 25]. These studies, however, used methacholine for bronchoprovocation. Hence, our study provides complementary information on quantitative measures of airway effects in the setting of higher levels of total serum IgE. We also found a greater degree of airway obstruction as measured by FEV1/FVC with higher levels of total serum IgE in Lima and not in Tumbes. This could be explained in part by the higher prevalence of asthma and atopy in Lima; however, in subset analyses, we observed that this relationship persisted among non-asthmatics in Lima. Our findings of an inverse relationship of total serum IgE to FEV1/ FVC are consistent with those of previous studies of asthmatics $[26,27]$. 
Our study has some potential shortcomings. First, our study design was cross-sectional. Therefore, we were not able to characterise the effects of early life exposures (including respiratory infections or environmental exposures in early childhood) on our observed relationships. Secondly, we did not conduct an evaluation of parasitic infections in our study children; however, previous population-based evaluations by our team on the burden of soil-based helminths in our study areas were found to be low (online supplementary material). Nonetheless, this low burden of parasitic infections, in light of elevated total serum IgE levels, needs to be further confirmed in future studies. Thirdly, our study did not include an evaluation of dietary habits or micronutrients, which may also have an effect on our observed relationships. However, our findings are largely consistent with a large, population-based study in the USA [12].

The relationship of total serum IgE to severity of airway obstruction is poorly understood. One possible explanation is that higher total serum IgE may reflect more severe asthma due to elevations in allergen-specific IgE levels. Another possibility is that elevated total serum $\operatorname{IgE}$ may also contribute indirectly to airway inflammation, which may help explain why we observed an inverse relationship of total serum IgE to FEV1/FVC among non-asthmatics living in Lima. In the Normative Aging Study, a longitudinal study of 2280 healthy adult volunteers in Boston without a history of asthma, skin test reactivity to four common aeroallergens was a significant predictor of decline in both FEV1 and FEV1/FVC [28]. Persistent exposure in sensitised individuals may be associated with chronic bronchial inflammation, which may help explain the findings of a reduced lung function over time in the Normative Aging Study. In the longitudinal Tucson Epidemiological Study of Airways Obstructive Disease, total serum IgE was not associated with a FEV1 decline in eversmokers without asthma [29]. Studies have shown that allergen exposure affects cytokine and anti-inflammatory production. Tumour necrosis factor-alpha, interleukin (IL)-6 and IL-8 are upregulated in airway epithelium after exposure to allergens [30]. A recent study comparing inflammatory markers in atopic versus non-atopic patients with chronic obstructive pulmonary disease found that IL-8 was upregulated in patients with mite allergies [31].

In summary, total serum IgE was associated with atopic asthma in a developing country setting despite high background levels of total serum IgE. Urbanisation did not appear to be an effect modifier of this relationship. Our study also confirms the lack of association between total serum IgE and non-atopic asthma. Despite the lack of association with nonatopic asthma, we found that total serum $\operatorname{IgE}$ was associated with markers of airway inflammation and lung function even among non-asthmatics living in an urban environment. Markers of airway obstruction such as response to bronchodilators, exhaled nitric oxide and FEV1/FVC were also associated with total serum IgE.

\section{SUPPORT STATEMENT}

This study was supported by a Johns Hopkins Center for Global Health Award and the Fogarty International Center Training Grant (Grant R24 TW007988). W. Checkley was supported by a Clinician Scientist Award from the Johns Hopkins University, a K99/R00 Pathway to Independence Award (R00HL096955) from the National Heart, Lung and Blood Institute, National Institutes of Health and by a contract (HHSN268200900033C) with the National Heart, Lung and Blood Institute, National Institutes of Health. N. Hansel and W. Checkley were further supported by a R01 grant from the National Institutes of Environmental Health Sciences (R01ES018845). C.L. Robinson was a Fogarty International Clinical Research Scholar during the time of this work and was further supported by Tufts University School of Medicine. L.M. Baumann was supported by a pre-doctoral NIH T35 Training Grant (T35AI065385).

\section{STATEMENT OF INTEREST}

Conflict of interest information can be found alongside the online version of this article at www.erj.ersjournals.com

\section{REFERENCES}

1 Braman SS. The global burden of asthma. Chest 2006; 130: 4-12.

2 Masoli M, Fabian D, Holt S, et al. The global burden of asthma: executive summary of the GINA Dissemination Committee Report. Allergy 2004; 59: 469-478.

3 Bousquet J, Bousquet PJ, Godard P, et al. The public health implications of asthma. Bull World Health Organ 2005; 83: 548-554.

4 Pearce N, Pekkanen K, Beasley R. How much asthma is really attributable to atopy? Thorax 1999; 54: 268-272.

5 Gruchalla RS, Pongracic J, Plaut M, et al. Inner City Asthma Study: relationships among sensitivity, allergen exposure, and asthma morbidity. J Allergy Clin Immunol 2005; 115: 478-485.

6 Rosenstreich DL, Eggleston P, Kattan M, et al. The role of cockroach allergy and exposure to cockroach allergen in causing morbidity among inner-city children with asthma. N Engl J Med 1997; 336: 1356-1363.

7 Bennich HH, Ishizaka HK, Johansson SG, et al. Immunoglobulin E: a new class of human immunoglobulin. Immunology 1968; 3: 323-324.

8 Burrows B, Martinez FD, Halonen M, et al. Association of asthma with serum IgE levels and skin-test reactivity to allergens. $N$ Engl J Med 1989; 320: 271-277.

9 Burrows B, Halonen M, Lebowitz MD, et al. The relationship of serum immunoglobulin E, allergy skin tests, and smoking to respiratory disorders. J Allergy Clin Immunol 1982; 70: 199-204.

10 Sunyer J, Anto JM, Soriano JB, et al. Total serum IgE is associated with asthma independently of specific IgE levels. Eur Respir J 1996; 9: 1880-1884.

11 Beeh KM, Ksoll M, Buhl R. Elevation of total serum immunoglobulin $\mathrm{E}$ is associated with asthma in nonallergic individuals. Eur Respir J 2000; 16: 609-614.

12 Gergen PJ, Arbes SJ Jr, Calatroni A, et al. Total IgE levels and asthma prevalence in the US population: results from the National Health and Nutrition Examination Survey 2005-2006. J Allergy Clin Immunol 2009; 124: 447-453.

13 Barron-Casella EA, Strunk RC, Hamilton RG, et al. Elevation of IgE in children with sickle cell disease is associated with doctor diagnosis of asthma and increased morbidity. J Allergy Clin Immunol 2011; 127: 1440-1446.

14 Houba V, Rowe DS. A comparison of African and European serum levels of immunoglobulin E. Bull World Health Organ 1973; 49: 539-545.

15 Visness CM, London SJ, Daniels JL, et al. Association of obesity with IgE levels and allergy symptoms in children and adolescents: results from the National Health and Nutrition Examination Survey 2005-2006. J Allergy Clin Immunol 2009; 123: 1163-1169.

16 Robinson CL, Baumann LM, Gilman RH, et al. Effects of varying degrees of urbanization on asthma, allergy and airways inflammation in a developing country setting. Thorax 2011; 66: 1051-1057.

17 Baumann LM, Robinson CL, Combe JM, et al. Effects of distance from a heavily transited avenue on asthma and atopy in a peri-urban shanty-town in Lima, Peru. J Allergy Clin Immunol 2011; 127: 875-882. 
18 Robinson CL, Baumann LM, Gilman RH, et al. The Peru Urban versus Rural Asthma (PURA) Study: methods and baseline quality control data for a cross-sectional investigation into the prevalence, severity, genetics, immunology, and environmental factors affecting adolescent asthma in Peru. BMJ Open 2012; 2: e000421.

19 Mata Fernández C, Fernández-Benítez M, Pérez Miranda M, et al. Validation of the Spanish version of the Phase III ISAAC questionnaire on asthma. J Investig Allergol Clin Immunol 2005; 15: 201-210.

20 Miller MR, Hankinson JL, Brusasco V, et al. Standardisation of spirometry. Eur Respir J 2005; 26: 319-338.

21 Jiménez JC, Fontaine J, Grzych JM, et al. Systemic and mucosal responses to oral administration of excretory and secretory antigens from Giardia intestinalis. Clin Diagn Lab Immunol 2004; 11: 152-160.

22 Pérez $\mathrm{O}$, Lastre $\mathrm{M}$, Bandera $\mathrm{F}$, et al. Evaluation of the immune response in symptomatic and asymptomatic human giardiasis. Arch Med Res 1994; 25: 171-177.

23 Celedon JC, Soto-Quiros ME, Hanson LA, et al. The relationship among markers of allergy, asthma, allergic rhinitis, and eczema in Costa Rica. Pediatr Allergy Immunol 2002; 13: 91-97.

24 Sunyer J, Antó JM, Sabrià J, et al. Relationship between serum IgE and airway responsiveness in adults with asthma. J Allergy Clin Immunol 1995; 95: 699-706.
25 Sears MR, Burrows B, Flannery EM, et al. Relation between airway responsiveness and serum $\operatorname{IgE}$ in children with asthma and in apparently normal children. N Engl J Med 1991; 325: 1067-1071.

26 Carroll WD, Lenney W, Child F, et al. Asthma severity and atopy: how clear is the relationship? Arch Dis Child 2006; 91: 405-409.

27 Haselkorn T, Szefler SJ, Simons FER, et al. Allergy, total serum immunoglobulin E, and airflow in children and adolescents in TENOR. Pediatr Allergy Immunol 2010; 21: 1157-1165.

28 Gottlieb DJ, Sparrow D, O'Connor GT, et al. Skin test reactivity to common aeroallergens and decline of lung function: The Normative Aging Study. Am J Respir Crit Care Med 1996; 153: 561-566.

29 Sherrill DL, Lebowitz MD, Halonen M, et al. Longitudinal evaluation of the association between pulmonary function and total serum IgE. Am J Respir Crit Care Med 1995; 152: 98-102.

30 Vroling AB, Duinsbergen D, Fokkens WF, et al. Allergen induced gene expression of airway epithelial cells shows a possible role for TNF- $\alpha$. Allergy 2007; 62: 1310-1319.

31 Tsai JJ, Liao EC, Hsu JY, et al. The differences of eosinophil- and neutrophil-related inflammation in elderly allergic and nonallergic chronic obstructive pulmonary disease. J Asthma 2010; 47: 1040-1044. 